\title{
Mortality of Adults on Antiretroviral Therapy with and without TB co- infection in Jimma University Hospital, Ethiopia: Retrospective Cohort Study
}

\author{
Jimma Likisa Lenjisa ${ }^{1 *}$, Sultan Suleman Wega ${ }^{2}$, Tefera Belachew Lema ${ }^{3}$ and Gemeda Abebe Ayana \\ ${ }^{1}$ Pharmacy Department, College of Medicine and Health Sciences, Ambo University, Ambo, Ethiopia \\ ${ }^{2}$ Pharmacy Department, College of Public Health and Medical Sciences, Jimma University, Jimma, Ethiopia \\ ${ }^{3}$ Population and Family Health Department, College of Public Health and Medical Sciences, Jimma University, Jimma, Ethiopia \\ ${ }^{4}$ Medical Laboratory and Pathology Department, College of Public Health And Medical Sciences, Jimma University, Jimma, Ethiopia
}

\begin{abstract}
Background: In this study, it was hypothesized that tuberculosis co-infection independently increases the risk of mortality in people living with HIV (PLWHs) even if they are on antiretroviral therapy (ART). Therefore, investigating this hypothesis among cohort of adult PLWHs in south west Ethiopia was the aim of the present work.
\end{abstract}

Methods: A cohort study was conducted from December to August 2012 at Jimma University Specialized Hospital (JUSH). PLWHs initiating ART between 2008 and 2011 were included using simple random sampling. The effect of TB co-infection on all-cause mortality was assessed using Cox proportional hazard model.

Results: In crude analysis, all-cause mortality of TB co-infected patients was higher by $6.5 \%(P=0.004)$. However, multivariate analysis showed that TB co-infection didn't increase mortality (AHR, 1.31(0.573-3.007), $P=0.52)$. Instead, factors which increased death were low baseline functional status, malnutrition, CD4 count $<100 \mathrm{cells} / \mathrm{mm}^{3}$ at the initiation of ART.

Conclusion: In this study, it was shown that TB co-infection didn't independently increase mortality provided that patient is on ART. Therefore, beside TB, addressing patient's nutritional status and intervention to facilitate early presentation to health facilities before they deteriorate functionally and immunologically is mandatory to reduce mortality on ART.

Keywords: HIV/TB Co-infection; ART; Mortality; JUSH; Ethiopia

\section{Introduction}

Progressive immunodeficiency during HIV infection put an individual on increased risk of developing other infections including tuberculosis (TB) which is the leading and deadly one if not identified and treated early [1]. Accordingly, an HIV positive individual has about $50 \%$ lifetime risk of developing active TB [2].

There were an about 1.1 million HIV positive new TB cases globally in 2010 of which $82 \%$ live in sub-Saharan Africa [3]. In Ethiopia, the proportion of HIV/TB co infection in the general population is significantly high with recent estimates ranging from $46 \%$ to $65 \%$ [4]. World health organization (WHO)reported that Ethiopia is seventh among top ten countries with the highest number of death from HIVassociated TB in 2011 [5].

Antiretroviral therapy (ART) remains one of the best strategies in reducing the double trouble imposed by HIV/TB co- infection. Evidence shows that ART can have a significant impact on the HIV and TB related morbidity and mortality in co-infected patients [6]. However, concomitant treatment is complicated by factors such as overlapping drug toxicities, drug-drug interactions and possible paradoxical reactions [7-9]. Likewise, these co-infected patients on concomitant treatment are at increased risk of decreased adherence to either or both treatments secondary to large pill burden [10]. The significant drug-drug interaction between standard TB medications and HAART could also result in sub therapeutic plasma concentration of either or both drugs. The cumulative effects of these complications could ultimately lead to poor virological, immunological and clinical treatment outcomes in these patient groups $[9,11,12]$.

There are limited literatures which compared mortality of HIV positive adults with TB co-infection on first line ART with those without TB co-infection. Amongst those few literatures available, majority of them are from developed countries [13-15] and published works on this issue in resource poor setting like Ethiopia is scarce [16-18]. In addition to this, the available evidences are not consistent regarding the effect of TB co-infection on mortality of people living with HIV (PLWHs) who are on effective first line ART.

Furthermore, sub-Sahara Africa including Ethiopia is continued to be the victim of death due to HIV/TB co-infection regardless of the widely available ART services and standard TB care highlighting the need for identifying and addressing factors rather than TB co-infection that could contribute to this death in PLWHs taking ART.

Therefore, in the present study, we tested the hypothesis which says TB co-infection independently and significantly increases mortality of PLWHs even if they are on ART and optimally adhered to such regimens. We have also investigated the effect of other factors on mortality in these patients beside TB co-infection early at 6 months and

*Corresponding author: Jimma Likisa Lenjisa, Pharmacy Department, College of Medicine and Health Sciences, Ambo University, Pobox 19, Ambo, Ethiopia, Tel: +251917305585; Fax: 251112365637; E-mail: jimmapharm@gmail.com

Received June 20, 2014; Accepted August 26, 2014; Published September 05, 2014

Citation: Lenjisa JL, Wega SS, Lema TB, Ayana GA (2014) Mortality of Adults on Antiretroviral Therapy with and without TB co-infection in Jimma University Hospital Ethiopia: Retrospective Cohort Study. J AIDS Clin Res 5: 350. doi:10.4172/21556113.1000350

Copyright: $\odot 2014$ Lenjisa JL, et al. This is an open-access article distributed under the terms of the Creative Commons Attribution License, which permits unrestricted use, distribution, and reproduction in any medium, provided the original author and source are credited. 
at the end of study period and put relevant recommendations for policy makers and ART programmer.

\section{Methods}

\section{Study setting}

This study was conducted in one of the largest teaching hospital in Ethiopia called Jimma University Specialized Hospital found in south western part of the country. There is separate ART and TB clinic in this hospital currently serving a total of 9809 (3519 on ART and 6290 pre-ART) PLWH including those with TB co-infection. At this clinic, patients have regular follow-up for medication refill, monitoring for drug adverse effects and possible treatment failure, adherence to medications, and to begin ART when the patients meet the criteria of ART treatment guideline of adults and adolescents. Weight, height, and other parameters are measured during each visit. Hemoglobin level, renal function test, liver function test and $\mathrm{CD} 4$ determination are being done initially, during pre-ART, at the time of ART initiation and every 6 months as per guideline [19]. However, until this study was conducted, viral load determination was not being done in this hospital and other part of the country except in some private hospitals because of resource limitation

\section{Study design}

A retrospective cohort study was conducted from December to August 2012, using ART patient master cards and computer database. All PLWH who were on ART at this clinic and started such treatment between January 2008 and March 2011 were our population. Of these, we included only adult PLWH (age $\geq 18$ years) who were on ART and had at least one follow up clinic visit after initiation of ART. Patients who had many of their records missed to the extent that it can affect analysis, patients who were lost for follow up and came back to treatment and patients with past history of TB and or completed TB treatment ahead of ART initiation or contracted TB within one month of ART initiation were excluded from the study.

Considering $90 \%$ power of study, $16 \%$ for possible incompleteness of the recordings, and $10 \%$ for lost to follow up, sample size was determined to be 650 using standard table for sample size determination in cohort studies [20]. Of total, 130 were PLWH with TB co-infection while the remaining were PLWHs with no TB co-infection when they started ART. Computer generated simple random sampling technique was employed to select the study participants.

\section{Data collection and design of collection tool}

Data collection was done using a pretested data abstraction format that was designed for the purpose of this study. Data was collected by well trained data collectors including two nurses and two pharmacists working in ART clinic of Jimma University Specialized Hospital (JUSH) up on the supervision of the principal investigator.

\section{Data analysis}

Data analysis was done using statistical package for social sciences (SPSS) version 16.0. All statistical tests were two-tailed, with $P<0.05$ considered significant. The two-groups were compared for All-cause mortality using both chi-square tests $\left(\mathrm{X}^{2}\right)$ and fisher's exact test. The survival probabilities were estimated by the method of KaplanMeier and compared using log-rank test for significance. The Coxproportional hazard regression model was used to examine the effect of TB co-infection on all-cause mortality of PLWHs taking first line ART at 6 months and at the end of follow up period.
Hazard ratios and 95\% confidence intervals (95\% CI) were also determined. Finally, the results were presented in the form of tables and figures. Categorical variables as number (\%) and continuous variables as mean \pm standard error of mean.

\section{Ethical approval}

Ethical clearance was obtained from the ethical review board of Jimma University College of Public Health and Medical Sciences. During data collection, any personally identifiable information was not included in the data collection format except the ART unique number of each patient to keep confidentiality.

\section{Results}

\section{Demographic and other baseline characteristics}

As Table 1 presents, analysis was made in comparison of two groups of PLWHs; with HIV/TB co-infection $(\mathrm{N}=130)$ and with only HIV $(n=520)$ at ART initiation. There is female predominance in both cases. It accounts for a total of $355(68.3 \%)$ and $74(56.9 \%)$ in patients without and with $\mathrm{TB}$ co infection respectively which is significantly different $(P=0.02)$. The mean age was $33.6 \pm 0.4$ and $33.4 \pm 0.8$ years respectively for patients without and with TB co-infection. The mean values of weight, CD4 cell count and body mass index (BMI) at ART initiation were all significantly higher for PLWHs with only HIV infection. Majority 45 (34.6\%) of PLWHs with TB co-infection had WHO stage IV conditions. Both groups of PLWHs were most commonly prescribed ART regimen comprising of non tenofovir (TDF) based regimens which accounted for $324(62.3 \%)$ and 77 (59.2\%) of the total regimens

\begin{tabular}{|c|c|c|c|c|}
\hline \multirow{2}{*}{ Variables } & \multirow{2}{*}{ Category } & \multicolumn{2}{|c|}{ TB Status } & \multirow[b]{2}{*}{${ }^{b} P$} \\
\hline & & ${ }^{a} \mathrm{NO}(\mathrm{N}=520)$ & YES $(N=130)$ & \\
\hline \multicolumn{2}{|c|}{ Age in year, Mean $\pm^{\circ}$ Std. Error of mean } & $33.6 \pm 0.4$ & $33.4 \pm 0.8$ & 0.85 \\
\hline \multirow[b]{2}{*}{ Gender } & Male, N (\%) & $165(31.7)$ & $56(43.1)$ & \multirow[b]{2}{*}{0.02} \\
\hline & Female, $\mathrm{N}(\%)$ & $355(68.3)$ & $74(56.9)$ & \\
\hline \multirow[b]{2}{*}{ Residence } & Rural, N (\%) & $125(24)$ & $35(26.9)$ & \multirow[b]{2}{*}{0.57} \\
\hline & Urban, N (\%) & $395(76)$ & $95(73.1)$ & \\
\hline \multirow{2}{*}{ Marital status } & Never married $\mathrm{N}(\%)$ & $102(19.6)$ & $26(20)$ & \multirow[b]{2}{*}{0.16} \\
\hline & Ever married, $\mathrm{N}(\%)$ & $418(80.4)$ & $56(43.1)$ & \\
\hline \multirow{3}{*}{ Educational level } & Illiterate/ Primary, N (\%) & $285(54.8)$ & $76(58.5)$ & \multirow{3}{*}{0.17} \\
\hline & Secondary, N (\%) & $175(33.7)$ & $39(30)$ & \\
\hline & Tertiary, N (\%) & $60(11.5)$ & $15(11.5)$ & \\
\hline \multirow{2}{*}{${ }^{d} \mathrm{WHO}$ stage } & Stage I-III, N (\%) & $491(94.4)$ & $85(65.4)$ & \multirow{2}{*}{$<0.001$} \\
\hline & Stage IV, N (\%) & $29(5.6)$ & $45(34.6)$ & \\
\hline \multirow{2}{*}{${ }^{e} \mathrm{ART}$ regimens } & 'TDF based & $196(37.7 \%)$ & $53(40.8 \%)$ & \multirow[b]{2}{*}{$<0.001$} \\
\hline & Non TDF based & $324(62.3 \%)$ & $77(59.2 \%)$ & \\
\hline \multirow{3}{*}{ Functional status } & Working, N (\%) & $378(72.7)$ & $51(38.7)$ & \multirow{3}{*}{$<0.001$} \\
\hline & Ambulatory, $\mathrm{N}(\%)$ & $127(24.4)$ & $66(50.8)$ & \\
\hline & Bed ridden, $\mathrm{N}(\%)$ & $15(2.9)$ & $13(10)$ & \\
\hline \multicolumn{2}{|c|}{ Weight in $\mathrm{kg}$, Mean \pm Std. error of mean } & $52.0 \pm 0.4$ & $49.1 \pm 0.8$ & 0.003 \\
\hline \multicolumn{2}{|c|}{$\begin{array}{l}\mathrm{CD} 4 \text { in cells } / \mathrm{mm}^{3} \text {, Mean } \pm \text { Std. error of } \\
\text { mean }\end{array}$} & $153.8 \pm 3.8$ & $128.7 \pm 9.7$ & 0.006 \\
\hline \multicolumn{2}{|c|}{${ }^{9} \mathrm{BMI}$ in $\mathrm{kg} / \mathrm{m}^{2}$, Mean \pm Std. error of mean } & $19.4 \pm 0.1$ & $18.2 \pm 0.3$ & $<0.001$ \\
\hline
\end{tabular}

Table 1: Characteristics of Study Participants at the Time of ART Initiation, December - August 2012, JUSH, Ethiopia.

a TB absent when therapy is initiated, ${ }^{b} \mathrm{p}$-value obtained from chi-square or student $t$-test analysis, ${ }^{c}$ standard error of mean, ${ }^{d}$ World Health Organization, antiretroviral therapy,

${ }^{f}$ tenofovir , ${ }^{g}$ body mass index, $\boldsymbol{N}$ is a denominator 
for patients without and with TB co-infection respectively. Majority of patients without TB co-infection were working 378 (72.7\%) whereas those with TB co-infection were ambulatory and bedridden making up a total of $79(60.8 \%)$. In this study, $418(80.4 \%)$ PLWHs without $\mathrm{TB}$ and $56(43.1 \%)$ those with TB at the time of ART initiation have ever experienced marriage. Even if majorities are urban dwellers yet significant number of them is illiterate or attaining only primary education (Clearly presented in Table 1).

\section{Comparison of mortality in the two groups using Kaplan Meier method}

In this study, crude analysis showed that all-cause mortality at the end of follow up period was found to be higher in PLWHs with TB co- infection; 13 (10.0\%) compared to those without TB; 18 (3.5\%) and this difference was statistically significant $(P=0.004)$. The cumulative probabilities of survival were also estimated by the method of KaplanMeier and found that patients without TB co-infection survived longer with cumulative survival of $96.4 \%$ compared to those with TB coinfection with cumulative survival of $89.4 \%$ and this difference was statistically significant $(P=0.001)$ (Figure 1 and Table 2$)$.

\section{Cox-Regression analysis to assess the impact of TB on mortality of PLWHs on ART}

In Cox-regression model too, without adjusting for other variables, TB co-infected patients had significantly higher hazard for death

\begin{tabular}{|c|c|c|c|c|c|}
\hline \multirow{2}{*}{\multicolumn{2}{|c|}{${ }^{a} A R T$ Outcomes }} & \multirow[t]{2}{*}{ Months } & \multicolumn{2}{|c|}{ TB Status } & \multirow{2}{*}{$\begin{array}{c}P \text { (Pearson } \\
\text { chi- } \\
\text { square) }\end{array}$} \\
\hline & & & $\begin{array}{c}{ }^{b} \mathrm{NO} \\
(\mathrm{N}=520)\end{array}$ & $\begin{array}{c}\text { YES } \\
(\mathrm{N}=130)\end{array}$ & \\
\hline \multirow[t]{3}{*}{${ }^{c}$ Attrition } & Died, n (\%) & 12 & $18(3.5)$ & $13(10.0)$ & .004 \\
\hline & Lost to follow up, n (\%) & 6 & $35(6.7)$ & $11(8.5)$ & .04 \\
\hline & & 12 & $14(3)$ & $8(7.5)$ & $<.001$ \\
\hline \multicolumn{2}{|c|}{$\begin{array}{l}\text { Cumulative probability of survival, } \\
\%\end{array}$} & 12 & 96.4 & 89.4 & .001 \\
\hline
\end{tabular}

${ }^{a}$ Antiretroviral therapy, ${ }^{b}$ there is no tuberculosis co-infection, ${ }^{c}$ death plus lost to follow up,

Table 2: Attrition and survival of PLWHs on ART compared based on TB status, December-August 2012, JUSH, Ethiopia

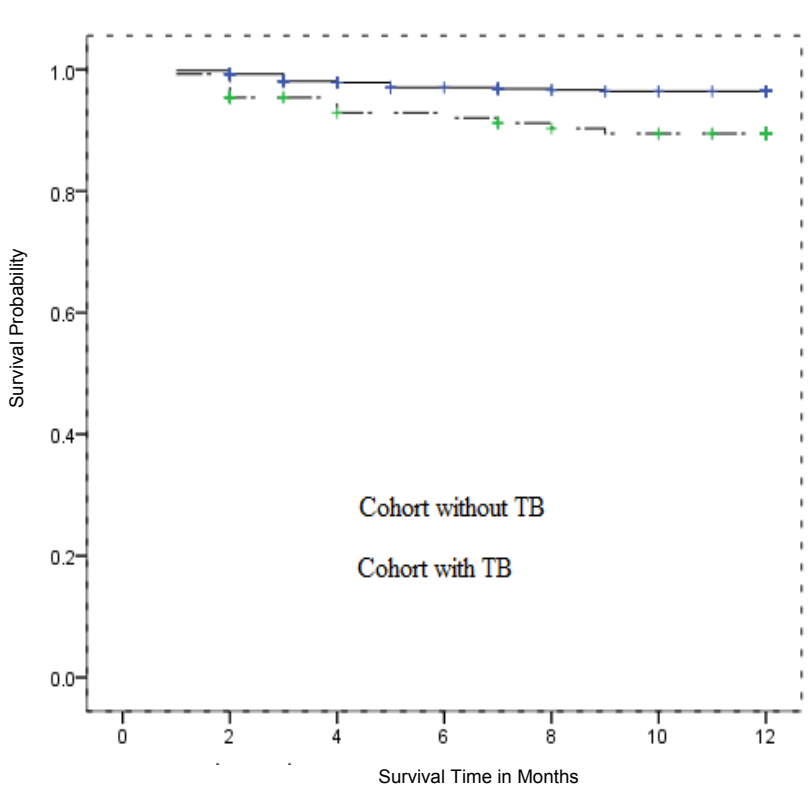

Figure 1: Kaplan-Meier curve comparing the overall survival rate of study cohorts with and without TB co-infection at the end of follow up period, December to August 2012, JUSH, Ethiopia.

(HR 3.06 (1.497-6.236), $P=0.002$ ) overall. However, after accounting for the confounding effects of other variables, TB co-infection didn't significantly increase the risk of death. Rather, the study showed that CD4 count $<100$ cells $/ \mathrm{mm}^{3}$ (AHR 2.95 (1.271-6.854), $\mathrm{P}=0.012$ ), being ambulatory (AHR 2.46 (2.114-6.909), $\mathrm{P}=0.024)$ and bedridden (AHR $5.06(1.632-15.659), \mathrm{P}=0.005)$ at ART initiation to be independent predictors of mortality in these patient groups at the end of study period. However, the effect of malnutrition was seen only during the early (at six months) follow up period and only marginally significant then after (Table 3 ).

\section{Discussion}

This study explored whether or not tuberculosis co-infection could

\begin{tabular}{|c|c|c|c|c|c|c|c|c|}
\hline \multirow{4}{*}{ Variable } & \multicolumn{8}{|c|}{ Follow up time in months } \\
\hline & \multicolumn{4}{|c|}{ At Six months of follow up visit } & \multicolumn{4}{|c|}{ At the end of the study period } \\
\hline & \multicolumn{2}{|c|}{ Univariate analysis } & \multicolumn{2}{|c|}{ Multivariate analysis } & \multicolumn{2}{|c|}{ Univariate analysis } & \multicolumn{2}{|c|}{ Multivariate analysis } \\
\hline & ${ }^{a} \mathrm{HR}(95 \% \mathrm{Cl})$ & ${ }^{b} \boldsymbol{P}$ & ${ }^{c} \mathrm{AHR}(95 \% \mathrm{Cl})$ & $P$ & $\operatorname{AHR}(95 \% \mathrm{Cl})$ & $P$ & $\operatorname{AHR}(95 \% \mathrm{Cl})^{d}$ & $P$ \\
\hline \multicolumn{9}{|c|}{ TB co-infection } \\
\hline Absent & Reference & --- & Reference & --- & Reference & ---- & Reference & ---- \\
\hline Present & $2.79(1.26-6.22)$ & 0.01 & $1.09(0.36-3.27)$ & .88 & $3.06(1.49-6.24)$ & 0.02 & $1.31(0.57-3.01)$ & .52 \\
\hline \multicolumn{9}{|c|}{ Functional status } \\
\hline Working & Reference & ---- & Reference & ---- & Reference & ---- & Reference & ------ \\
\hline Ambulatory & $6.55(2.09-20.57)$ & 0.001 & $5.53(1.11-27.52)$ & .04 & $3.29(1.19-9.05)$ & 0.02 & $2.46(2.11-6.91)$ & .02 \\
\hline Bed ridden & $6.96(1.42-14.60)$ & $<0.001$ & $6.25(1.40-14.47)$ & $<.01$ & $9.34(3.18-27.48)$ & $<0.01$ & $5.06(1.63-15.66)$ & .01 \\
\hline \multicolumn{9}{|c|}{${ }^{e}$ BMI category in $\mathrm{kg} / \mathrm{m}^{2}$} \\
\hline$\geq 18.5$ & Reference & --- & Reference & ---- & Reference & ---- & Reference & ---- \\
\hline $16-17$ & $4.32(1.67-11.21)$ & .003 & $4.47(1.39-14.39)$ & .01 & $3.04(1.26-7.34)$ & .01 & $2.52(1.35-8.95)$ & .06 \\
\hline$<16$ & $3.68(1.31-10.35)$ & .01 & $1.51(0.39-5.84)$ & .55 & 3.08 (1.28- 7.45$)$ & 0.01 & $3.40(1.64-12.34)$ & .08 \\
\hline \multicolumn{9}{|c|}{ CD4 category in cells $/ \mathrm{mm}^{3}$} \\
\hline$<100$ & $5.42(1.77-12.32)$ & .005 & $3.90(1.67-9.24)$ & .01 & $6.41(2.87-14.34)$ & $<0.01$ & $2.95(1.27-6.85)$ & .01 \\
\hline$\geq 100$ & Reference & ---- & Reference & --- & Reference & ----- & Reference & ----- \\
\hline
\end{tabular}

${ }^{a}$ Crude hazard ratio, ${ }^{b}$ p-value obtained by Cox regression, ${ }^{c}$ djusted hazard ratio, ${ }^{d}$ confidence interval at $95 \%$, ${ }^{e}$ body mass index

Table 3: Cox-Proportional Hazard Model for Assessing the Effect of TB co-infection on Mortality of PLWHs receiving ART, December-August 2012, JUSH, Ethiopia. 
significantly and independently increase the risk of mortality in cohort of PLWHs while they are taking first line ART and fully adhered to such treatment. Therefore, the major findings of this study were discussed below in comparison to other previously published works.

In Sub-Sahara African, early mortality rates are very high where $8-26 \%$ of patients die in the first year of antiretroviral treatment, with most deaths occurring in the first few months [21] secondary to several factors including but not limited to severe immunodeficiency which in turn leads to fatal opportunistic infections such as tuberculosis, late presentation to health facility and non-adherence to their ART regimens.

In this study, all cause mortality for the study PLWHs, in crude analysis was significantly higher for patients with TB co infection at the end of the study period. Similar findings were shown in Taiwan [13] and South Africa [18,22]. In contrast, study in India recently reported that mortality outcome was similar regardless of the presence or absence of TB co infection when ART is initiated [15]. The low power of their study might be the reason for failure to detect the difference. Similarly, study in Zambia reported no difference in mortality rates by TB status at baseline even though the authors acknowledged that the result may have been affected by the substantial number of lost to follow up occurred in the study participants [23].

Study showed that the survival rate of HIV-TB co-infection increased to $86.60 \%$ during the ART era [24]. Similarly, it is observed that ART had brought a substantial reduction in deaths during TB treatment for HIV infected TB patients in Thailand [25]. In the present study also the survival benefit of ART is further demonstrated in both groups of PLWHs even to greater extent than the one reported in aforementioned studies.

However, Kaplan Meier comparison showed the survival rate observed in this study is greater for patients without TB co infection. This finding is comparable with study in India [15], Taiwan [13] and South Africa [18]. The lower survival rate in cohort with TB observed in this study could be due to the fact that TB patients are more likely to have severe immunosuppression (low CD4 counts), low BMI, and anemia when ART initiated than others. Other studies also complement this fact $[18,21,26,27]$. Even if the overall survival rate is lower for PLWHs with TB co-infection at the time of ART initiation, the presence of TB co infection was not found to increase the risk of death after accounting for the effect of other confounding factors in Cox-regression model. Other published studies in Taiwan [3], Malawi [17] and South Africa [18] have also shown similar findings.

Similarly, meta analysis of six studies in HIV/TB co infected patient showed that tuberculosis doesn't show an effect on mortality in PLWH on ART [22]. Studies in Mozambique [28] and Tanzania [29] also showed that active TB co infection hasn't increased attrition (death and or Lost to follow up) risk in PLWH after initiating ART. Therefore these findings pinpoint HIV programmers and policy makers that the mere presence of TB at the time of ART initiation doesn't compromise the survival benefits of ART. Instead there are some factors found to be silent killers of PLWHs receiving ART in resource limited settings. In this regard, the present study uncovered three important factors which independently increased the risk of mortality among PLWHs on ART. These include lower base line functional status (being ambulatory and bedridden), malnutrition and severe immunosuppression at ART initiation.

Functional status represents how sick the patients were at baseline; lower baseline functional status implies advanced disease and thus may explain its association with higher risk of death [30]. Similarly, other studies in Ethiopia [27,31] showed that there is higher mortality in patients with lower baseline functional status similar to the present study. Two other studies in Africa showed that patients who experienced severe morbidity and hence poor performance at presentation to health facilities had higher risks of mortality [32,33] highlighting the need for early presentation and screening for HIV as well as TB of the general population in Africa.

One study in sub-Saharan Africa showed malnutrition was factors independently increasing the risk of mortality on HAART [34]. In present study, similarly, it was found to have increased the risk of mortality. In accordance with this, a retrospective cohort study in Singapore also showed that moderate to severe malnutrition is a significant independent predictor of death in PLWHs on ART [35]. In the present study, the impact of malnutrition was seen during the early six months of initiating HAART and disappeared thereafter. This highlights the importance of fostering the early nutritional support such as the provision of formula foods as well as advice on appropriate diet for such patients.

Late after 6 months of ART initiation, low baseline functional status continued to increase mortality risk and CD4 cell count of less than 100 cells $/ \mathrm{mm}^{3}$ appeared to increase mortality risk only at this time. This finding was comparable to results of two retrospective cohort studies in Eastern Ethiopia [26,27]. This clearly indicates that ART should be initiated as early as possible such as before CD4 counts drop down to 200 cells $/ \mathrm{mm}^{3}$. This is also a clue for a need of fostering continuing health education regarding HIV counseling and test to promote screening for both HIV and TB before the development of advanced disease.

Limitations of the present study primarily relate to the fact that analyses were based on routinely collected data, which were incomplete for certain baseline and follow-up clinical characteristics. Hence, there could be inherent unmeasured risk factors which could confound the effects of other variables. Another limitation is that there could be misclassification bias as it is not easy to diagnosis TB in HIV positive patients. As a result, HIV/TB co-infected patients may be treated only for HIV and also only HIV infected patients may be treated wrongly for $\mathrm{TB}$ as well. However, retrospective cohort studies are playing vital role in changing guide lines as they are cheap to conduct and don't require longer time.

\section{Conclusion}

Generally, the findings of the present study are in accordance with other previously published data. It seems that patients with TB coinfection when initiated first line antiretroviral regimens more likely to experience death and survive shorter compared to patients without TB co-infection. Nevertheless, after fitting multivariate Cox-regression model, the presence of TB co-infection didn't independently increase the risk of death confirming the survival advantage of initiating ART during TB treatment. Therefore, to further ensure the survival benefit of ART, we have to address those neglected yet very important determinants of mortality like deteriorated immunity, lower functional status and malnutrition in PLWHs on ART while still fostering the attempts to control over tuberculosis.

\section{Funding}

This work was supported by Jimma University, college of public health and medical sciences

\section{Acknowledgement}

We would like to acknowledge the health care providers as well as other staff 
Citation: Lenjisa JL, Wega SS, Lema TB, Ayana GA (2014) Mortality of Adults on Antiretroviral Therapy with and without TB co-infection in Jimma University Hospital, Ethiopia: Retrospective Cohort Study. J AIDS Clin Res 5: 350. doi:10.4172/2155-6113.1000350

members working in antiretroviral therapy clinics of Jimma University specialized hospital without whom this study would not have been possible.

\section{References}

1. World Health Organization (2010) Priority research questions for TB/HIV in HIV-prevalent and resource-limited settings. WHO, Geneva, switzerland.

2. World Health Organizatio (WHO) (2004) Stop TB Department, Department of HIVIAIDS, Department of Child and Adolescent Health and Development. TB/ HIV a Clinical Manual. WHO, Geneva, switzerland.

3. World Health Organization (2012) TB/HIV FACTS 2011-2012. WHO, Geneva, switzerland.

4. Abera B, Kate F, Zelalem H (2009) The association of TB with HIV infection in Oromia Regional State, Ethiopia in 2006/7. Ethiop J Health Dev 23: 63-67.

5. World Health Organization (2011) Time to act and save a million lives by 2015 Prevent and treat tuberculosis among people living with HIV. WHO, Geneva, Switzerland.

6. Rajasekaran S, Raja K, Jeyaseelan L, Vijilat S, Priya K, et al. (2009) PostHAART tuberculosis in adults and adolescents with HIV in India: incidence, clinical and immunological profile. Indian J Tuberc 56: 69-76.

7. Kwara A, Flanigan TP, Carter EJ (2005) Highly active antiretroviral therapy (HAART) in adults with tuberculosis: current status. Int J Tuberc Lung Dis 9 : 248-257.

8. Abdool Karim SS, Naidoo K, Grobler A, Padayatchi N, Baxter C, et al. (2011) Integration of antiretroviral therapy with tuberculosis treatment. $\mathrm{N}$ Engl $\mathrm{J}$ Med 365: 1492-1501.

9. Piggott DA, Karakousis PC (2011) Timing of antiretroviral therapy for HIV in the setting of TB treatment. Clin Dev Immunol 2011: 103917.

10. Gebremariam MK, Bjune GA, Frich JC (2010) Barriers and facilitators of adherence to TB treatment in patients on concomitant TB and HIV treatment: a qualitative study. BMC Public Health 10: 651

11. Lawn SD, Myer L, Bekker LG, Wood R (2006) Burden of tuberculosis in an antiretroviral treatment programme in sub-Saharan Africa: impact on treatment outcomes and implications for tuberculosis control. AIDS 20: 1605-1612.

12. Moore D, Liechty C, Ekwaru P, Were W, Mwima G, et al. (2007) Prevalence, incidence and mortality associated with tuberculosis in HIV-infected patients initiating antiretroviral therapy in rural Uganda. AIDS 21: 713-719.

13. Hung CC, Chen MY, Hsiao CF, Hsieh SM, Sheng WH, et al. (2003) Improved outcomes of HIV-1-infected adults with tuberculosis in the era of highly active antiretroviral therapy. AIDS 17: 2615-2622.

14. Breen RA, Miller RF, Gorsuch T, Smith CJ, Ainsworth J, et al. (2006) Virological response to highly active antiretroviral therapy is unaffected by antituberculosis therapy. J Infect Dis 193: 1437-1440.

15. Sanjiv K, Shah N, Dhooria S, Ravi A, Sinha S, et al. (2011) The antiretrovira efficacy of highly active antiretroviral therapy and plasma nevirapine concentrations in HIV-TB co-infected Indian patients receiving rifampicin based antituberculosis treatment. AIDS Research and Therapy 8:41.

16. Zanoni BC, Phungula T, Zanoni HM, France H, Feeney ME (2011) Impact of tuberculosis cotreatment on viral suppression rates among HIV-positive children initiating HAART. AIDS 25: 49-55.

17. Bong CN, Chen SC, Jong YJ, Tok TS, Hsu CF, et al. (2007) Outcomes of HIVinfected children with tuberculosis who are started on antiretroviral therapy in Malawi. Int J Tuberc Lung Dis 11: 534-538.

18. Westreich D, MacPhail P, Van Rie A, Malope-Kgokong B, Ive P, et al. (2009) Effect of pulmonary tuberculosis on mortality in patients receiving HAART. AIDS 23: 707-715.

19. World Health Organization (2006) Antiretroviral Therapy for HIV Infection in Adults and Adolescents: Recommendations for a public health approach. Geneva, Swizerland, WHO.
20. Strom LB (2005) Pharmacoepidemiology: Tables of sample size for cohort studies. (3rd Edn.) John Wiley and Sons. England.

21. Lawn SD, Harries AD, Anglaret X, Myer L, Wood R (2008) Early mortality among adults accessing antiretroviral treatment programmes in sub-Saharan Africa. AIDS 22: 1897-1908.

22. Straetemans $M$, Bierrenbach $A L$, Nagelkerke N, Glaziou $P$, van der Werf $M$ (2010) The effect of tuberculosis on mortality in HIV positive people: a metaanalysis. PLoS One 5: e15241.

23. Stringer JS, Zulu I, Levy J, Stringer EM, Mwango A, et al. (2006) Rapid scaleup of antiretroviral therapy at primary care sites in Zambia: feasibility and early outcomes. JAMA 296: 782-793.

24. Tseng SH, Jiang DD, Hoi HS, Yang SL, Hwang KP (2009) Impact of HAART therapy on co-infection of tuberculosis and HIV cases for 9 years in Taiwan. Am J Trop Med Hyg 80: 675-677.

25. Akksilp S, Karnkawinpong O, Wattanaamornkiat W, Viriyakitja D, Monkongdee $\mathrm{P}$, et al. (2007) Antiretroviral therapy during tuberculosis treatment and marked reduction in death rate of HIV-infected patients, Thailand. Emerg Infect Dis 13: 1001-1007.

26. Tsegaye D (2012) Survival and Predictors of Mortality in Adults on Antiretroviral Therapy in Selected Public Hospitals in Harar, Ethiopia. Harar Bulletin of Health Sciences.

27. Biadgilign S, Reda AA, Digaffe T (2012) Predictors of mortality among HIV infected patients taking antiretroviral treatment in Ethiopia: a retrospective cohort study. AIDS Res Ther 9: 15.

28. Auld AF, Mbofana F, Shiraishi RW, Sanchez M, Alfredo C, et al. (2011) Fouryear treatment outcomes of adult patients enrolled in Mozambique's rapidly expanding antiretroviral therapy program. PLoS One 6: e18453.

29. Mossdorf E, Stoeckle M, Mwaigomole GE, Chiweka E, Kibatala LP, et al (2011) Improved antiretroviral treatment outcome in a rural African setting is associated with combined ART initiation at higher CD4 cell counts and better general health condition. BMC Infectious Diseases 11: 98.

30. Mugusi FM, Mehta S, Villamor E, Urassa W, Saathoff E, et al. (2009) Factors associated with mortality in HIV-infected and uninfected patients with pulmonary tuberculosis. BMC Public Health 9: 409.

31. Tesfaye $M$, Bernt $L(2000)$ The impact of functional performance, HIV status, malnutrion, and clinical features on treatment outcomes of patients with pulmonary tuberculosis. Ethiop J Health Dev 14:177-182.

32. Lawn SD, Bekker LG, Myer L, Orrell C, Wood R (2005) Cryptococcocal immune reconstitution disease: a major cause of early mortality in a South African antiretroviral programme. AIDS 19: 2050-2052.

33. Moh R, Danel C, Messou E, Ouassa T, Gabillard D, et al. (2007) Incidence and determinants of mortality and morbidity following early antiretroviral therapy initiation in HIV-infected adults in West Africa. AIDS 21: 2483-2491.

34. May M, Boulle A, Phiri S, Messou E, Myer L, et al. (2010) Prognosis of patients with HIV-1 infection starting antiretroviral therapy in sub-Saharan Africa: a collaborative analysis of scale-up programmes. Lancet 376: 449-457.

35. Paton NI, Sangeetha S, Earnest A, Bellamy R (2006) The impact of malnutrition on survival and the CD4 count response in HIV-infected patients starting antiretroviral therapy. HIV Med 7: 323-330. 